rev.relac.int.estrateg.segur.13(1):195-219,2018

\title{
Governança desportiva: uma inflexão da governança global?*
}

\author{
Juliano Oliveira Pizarro**
}

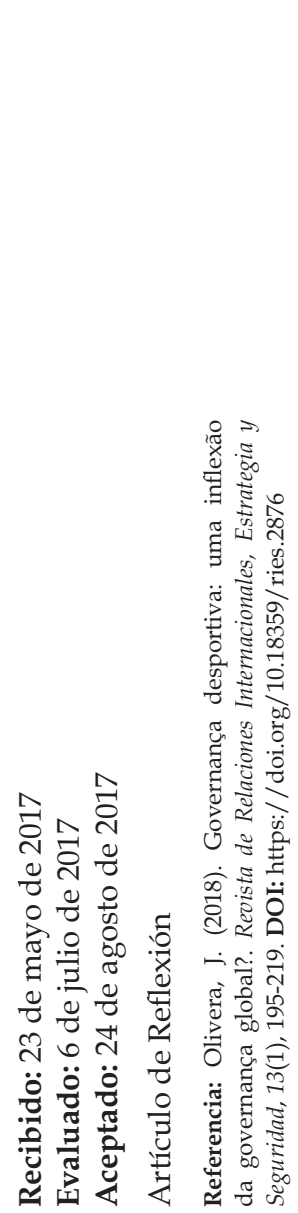

\section{Resumo}

É a partir da percepção da chamada governança global que a presente pesquisa parte, onde há espaço para o surgimento de diversosatores-queexercem governanças específicas- compreendendo nesse cenário o esporte e especialmente o futebol como um importante mecanismo social e cultural que sofre impactos diretos dos processos de globalização. A pesquisa baseia-se em fontes bibliográficas, documentais, sites e pesquisas já realizadas sobre o objeto. Observou-se que entidades de governança desportiva, em especial a Fédération Internationale de Football Association (FIFA), são organizações não -governamentais que se auto apresentam como instituições sem fins lucrativos, apesar do comportamento oscilar por vezes como mercado, expressando características híbridas e contraditórias na

\footnotetext{
O presente artigo é resultado da pesquisa de mestrado em Ciência Política da Universidade Federal de Pelotas e financiado através de bolsa de estudos pela Coordenação de Aperfeiçoamento de Pessoal de Nível Superior (CAPES) do Brasil.

** Doutorando em Ciências Humanas pela Universidade Federal de Santa Catarina, mestre em Ciência Política pela Universidade Federal de Pelotas, bacharel em Direito pela Universidade Federal de Pelotas. E-mail: jopizarro@hotmail.com
} 
dinâmica da governança global- ora como empresa multinacional, ora como organização do Terceiro Setor, ora como instituição internacional.

Palavras-chave: relações internacionais; governança global; governança desportiva; terceiro setor.

\title{
Gobernanza del deporte: ¿una inflexión de la gobernanza global?
}

\section{Resumen}

Es a partir de la percepción de la llamada gobernanza global que parte la investigación actual, donde hay espacio para el surgimiento de diferentes actores -que realizan gobernanzas específicas- incluyendo en este escenario el deporte y especialmente el fútbol como un mecanismo social y cultural importante, que es directamente afectada por los procesos de globalización. La investigación se basa en fuentes bibliográficas, documentales, sitios web e investigaciones ya realizadas sobre el objeto. Se observó que los órganos de gobierno deportivos, en especial la FIFA, son organizaciones no gubernamentales que se presentan como instituciones sin fines de lucro, a pesar del comportamiento que oscile a veces como mercado, expresando características híbridas y contradictorias en la dinámica de la gobernanza global, ora como una multinacional, ora como una organización del Tercer Sector, ora como una institución internacional.

Palabras clave: relaciones internacionales; gobernanza global; gobernanza del deporte; tercer sector.

\section{Sports governance: inflection of the global governance?}

\begin{abstract}
It is from the perception of called global governance that the research part, where there is a space for the emergence of different actors -that perform specific governances- including in this scenario the sport, especially the football, as an important social and cultural mechanism that is directly impacted for globalization processes. The research is based on sources bibliographical, documentary, websites and research already carried out on the object. It was observed that sport governance bodies, in particular FIFA, non-governmental organizations have as non-profit institutions, despite the behavior oscillate sometimes as market, expressing hybrid and contradictory characteristics in the dynamics of global
\end{abstract}


governance - as a multinational company, or as the Third Sector organization, or as an international institution.

Keywords: international relations; global governance; sports governance; third sector.

\section{Introdução}

O termo "governança" denota instituições políticas formais que visam coordenar e controlar as práticas do governo e que têm a capacidade de impor as suas decisões. Rosenau (2000) utilizou de forma pioneira a ideia de "governança" para explicar o funcionamento das relações interdependentes na ausência de uma autoridade política global, nos primórdios dos anos 1990.

É a partir da percepção desse contexto global "sem governo" que a presente pesquisa parte, onde há espaço para o surgimento de diversos atores -que exercem governanças específicascompreendendo nesse cenário o esporte e especialmente o futebol como um importante mecanismo social e cultural que sofre impactos diretos dos processos de globalização. A justificativa para a escolha do objeto de pesquisa dá-se por sua crescente importância e poder -político e simbólico- na governança desportiva e global do esporte, tanto o Comitê Olímpico Internacional (COI) como, principalmente, a Fédération Internationale de Football Association (FIFA).

Além da própria relevância do esporte e do futebol para a compreensão das relações sociais, políticas e culturais no âmbito das Ciências Sociais, tem-se uma série de questões relacionadas à soberania nacional e ingerência política quando da realização das Copas do Mundo no interior dos Estados-nação sedes. O Brasil as testemunhou antes e durante todo o ano de 2014. O esporte e o soft power andam juntos, pois os valores do esporte são símbolos utilizados no âmbito global, fazendo com que os órgãos de governança desportiva sejam atores importantes a serem observados nas relações internacionais, com atuações na atual governança global.
Algumas entidades que ganharam destaque nesse cenário são os ór- gãos de governança desportiva, e é nesse contexto que há a neces- sidade de estudos que percebam o esporte como um ato político. Ao longo da história do século XX o futebol foi popularizado e difundi- do devido seu baixo custo econô- mico e a facilidade de sua prática. E ao mesmo tempo em que se di- fundia e popularizava, o futebol se institucionalizou. De fato, foi o crescimento como espaço de so- ciabilidade que o transformou tam- bém em um espaço de interesses políticos e econômicos. (Magal- hães, 2013, p. 37) 
Através de duas dimensões de análise -Governança Global e Governança Desportiva-, a pesquisa baseia-se em fontes bibliográficas, documentais, sites e pesquisas já realizadas sobre o objeto. Emprega-se uma abordagem qualitativa de pesquisa documental, com o objetivo de identificar a inflexão dos órgãos de governança desportiva no cenário internacional, cujo comportamento expressa características híbridas na dinâmica da Governança Global -ora como empresa multinacional, ora como organização do Terceiro Setor, ora como instituição internacional.

Atualmente, o futebol possui um dos mercados que mais movimenta a economia mundial, sendo a FIFA - uma das principais entidades de governança desportiva no mundo- responsável por intermediar e fiscalizar muitas dessas transações. Através da simbologia do futebol, exerce influência nos âmbitos político, econômico e cultural.

\section{Esporte e Relações Internacionais contemporâneas: impactos da globalização}

O esporte é, de maneira geral, um elemento perceptível no processo de globalização da cultura. Pode ser utilizado como um recurso de política externa, constituindo-se um espaço interessante onde as relações internacionais têm lugar, pois existe uma variedade de contextos e significados que se pode explorar através do esporte na política mundial. Alguns estudiosos apontam o esporte como um dos fenômenos cul- turais mais importantes do século XX (Houlihan, 1994, p. 52).

A partir disso, o esporte pode ser considerado como tendo um fator positivo na governança global no sentido de integração. Elias e Dunning (1992, pp. 335 e 336) apontam que o ser humano gosta de jogar e, com o desenvolvimento da cultura ao longo da história, o jogo se "civilizou" com a colocação de ordem por meio de regras escritas, árbitros, tribunais e sanções claramente definidas.

Dentro desse contexto, ocorre no esporte a formação daquilo que Bourdieu (1983) denominou de campo esportivo. Para ele, é necessário compreender quais panoramas sociais permitiram que se constituísse o sistema de instituições. Bourdieu (1983) afirma que:

[...] a história do esporte é uma história relativamente autônoma que, mesmo estando articulada com os grandes acontecimentos da história econômica e política, tem seu próprio tempo, suas próprias leis de evolução, suas próprias crises, em suma, sua cronologia específica. Isto quer dizer que uma das tarefas mais importantes da história social do esporte poderia ser a sua própria fundação, fazendo a genealogia histórica da aparição de seu objeto como realidade específica irredutível a qualquer outra. (p. 137)

De acordo com Bourdieu (1986, apud Bracht, 2005, pp. 53 e 54) processos 
econômicos foram determinantes para a transição do esporte enquanto uma prática reservada à elite para o esporte-espetáculo, onde houve a profissionalização e, consequentemente, alterações nas relações de poder no interior desse campo. Como ocorreu uma popularização do esporte, as classes privilegiadas buscaram manter o capital político através do controle da indústria esportiva. A elite que comanda as entidades desportivas pode transformar, na linguagem de Bourdieu, o capital social obtido na administração esportiva em capital político, como dirigentes de federações esportivas que possuem aspirações políticas. Essa breve noção sociológica é importante para se entender a evolução do esporte historicamente na sociedade, mas não é o foco da presente pesquisa.

Em um contexto do esporte na atualidade, Suppo (2012) afirma:

Atualmente, o novo sistema midiático globalizado da chamada "era da informação" é um novo campo de enfrentamento onde ocorre o embate entre os Estados, as empresas transacionais e os novos movimentos sociais. O poder, num mundo dominado pelo sistema midiático, consiste em grande parte no controle da produção e na manipulação de símbolos que possam seduzir. Dessa forma, o imenso poder de sedução do esporte e seu impacto econômico não podem hoje ser ignorados pelos Estados nem pela indústria cultural. Nesse sentido, a geopolítica do esporte encontra-se no centro das disputas e rivalidades nacionais e internacionais, mas também, paradoxalmente, pode servir como vetor da paz e da cooperação [...]. (p. 420)

Barrie Houlihan, professor da Universidade de Loughborough na Inglaterra, é um dos grandes estudiosos da temática esporte e relações internacionais. Ele estabelece um panorama geral da relação entre as três teorias aplicadas às Relações Internacionais com o esporte, objetivando apresentar como as teorias do realismo, pluralismo e globalismo poderiam compreender o papel do esporte no cenário internacional.

Diante da análise que se fará a seguir, Suppo (2012) afirma que:

Para tal fim, em primeiro lugar, estabelece uma tipologia, a partir dos três tipos de atores ou agentes nas relações internacionais (Estados e organizações internacionais governamentais; organizações não governamentais internacionais; indivíduos) e do grau de envolvimento e interação dos diferentes recursos (finanças, indivíduos, conhecimento/cultura e território). Em segundo lugar, o autor conclui que a abordagem teórica mais adequada para tratar do tema do esporte nas relações internacionais é o pluralismo. O realismo e o globalismo seriam paradigmas menos convenientes por centralizarem as explicações num único fator. $\mathrm{O}$ 
primeiro, nas questões políticas e tendo seu foco de análise centrado em um único ator, o Estado, e com uma preocupação concentrada na segurança. O segundo, nas relações econômicas de dependência e dominação. (p. 415)

Suppo (2012, p. 418), baseado nas ideias de Houlihan, mostra uma relação dessas teorias aplicadas das relações internacionais ao esporte, onde os paradigmas teóricos possuiriam interesses específicos. O realismo se constata no uso do esporte como instrumento da política externa - através de elementos como o reconhecimento da soberania nacional, como uma válvula de segurança em momentos de tensão internacional e, ainda, como meio para melhorar as relações entre os Estados - na relação esporte e identidade nacional e, por fim, o esporte considerado como uma parte do "cultural package" não militar, essencial no estabelecimento e manutenção da hegemonia das grandes potências. $\mathrm{O}$ pluralismo aparece no papel das organizações não governamentais do esporte (por exemplo, COI e FIFA) como atores independentes na política internacional e suas interações com os Estados e no papel da mídia esportiva. Por fim, o globalismo se observa no papel das corporações multinacionais ligadas ao esporte (marketing, mídia, equipamento esportivo etc.) na dominação do capitalismo global, na exportação de esportistas talentosos dos países pobres para os países ricos e como meio de ação do imperialismo cultural.

\section{Governança desportiva: atores, discurso e gestão empresarial}

Diante de uma prática reconhecidamente importante como é o esporte, houve ao longo do século XX sua profissionalização. Com isso, houve também o surgimento de diversos organismos que se tornaram responsáveis pela governança das mais diversas práticas desportivas. Hums e MacLean (2009, p. 04) definem governança no esporte como o exercício do poder e da autoridade em uma organização esportiva, incluindo a formulação de políticas, a determinação da missão da organização, regras de afiliação, regras de elegibilidade e poder regulatório dentro de um escopo determinado como local, nacional ou internacional.

Dentro da ótica dos organismos que surgem, há também alguns que já existem há algum tempo e vêm criando força no cenário internacional. Como alguns, podemos citar os órgãos de governança desportiva das mais diversas modalidades. Esses órgãos são denominados Federações Desportivas Internacionais (Fls) e são responsáveis pela integridade do seu desporto a nível internacional, submissas ao Comitê Olímpico Internacional (inclusive a FIFA), as quais possuem federações nacionais da modalidade.

As federações nacionais que administram esses esportes são filiadas a eles. Conservando a sua independência e autonomia na administração de seus esportes, federações desportivas internacionais buscando o reconhecimento do 
COI deve garantir que os seus estatutos, práticas e atividades estejam em conformidade com a Carta Olímpica. Como consta no site do COI (2015) afirma que as federações desportivas internacionais são organizações não-governamentais internacionais reconhecidos por ele como a administração de um ou mais esportes a nível mundial.

As Fls têm a responsabilidade e o dever de gerenciar e monitorar o funcionamento diário de várias disciplinas desportivas do mundo, inclusive para aqueles sobre o programa, a organização prática de eventos durante os Jogos. Cada Fl deve também supervisionar o desenvolvimento de atletas praticantes desses esportes em todos os níveis. Elas regem o seu desporto a nível mundial e garante a sua promoção e desenvolvimento. Eles monitoram a administração cotidiana de seus esportes e garantir a organização regular de competições, bem como o respeito pelas regras de fair play.

As Fls podem formular propostas dirigidas ao COI sobre a Carta Olímpica e ao Movimento Olímpico em geral, incluídos a organização e realização dos Jogos Olímpicos. Podem também dar as suas opiniões sobre as candidaturas para organizar os Jogos Olímpicos, em especial sobre as capacidades técnicas das cidades candidatas, além de colaborar na preparação dos Congressos Olímpicos e participar nas atividades das comissões do COI.

A fim de discutir problemas comuns e decidir sobre seus eventos de ca- lendários, as reconhecidas federações de esportes de verão e inverno formaram associações. A partir de então surgiram: Associação das Federações Internacionais dos Esportes Olímpicos de Verão (ASOIF), Associação das Federações Internacionais dos Esportes Olímpicos de Inverno (AIOWF), a Associação das Federações Desportivas Internacionais reconhecidas pelo COI (ARISF) e da SportAccord, que também inclui outras federações desportivas.

De maneira geral, as grandes entidades de governança desportiva possuem confederações filiadas, as quais possuem federações internacionais, sendo essas os órgãos responsáveis pela organização da modalidade esportiva, possuindo o poder de legitimar as competições e de estabelecer as regras gerais do esporte. Segundo Ribeiro (2012):
A lógica é a representação de atletas e organizações, que se reúnem em torno de uma associação local nor- malmente denominada Federação, que dispõe de uma base territo- rial definida e pretende congregar todos os praticantes na região. As Confederações reúnem várias Fe- derações ou outras agremiações em uma organização nacional, repre- sentando os interesses do esporte em um dado país. (p. 22)

Toda atividade desportiva é precedida de uma série de regras, as quais devem ser respeitadas pelos competidores a fim de garantir uma competição justa. Em razão disso, existe a necessidade 
de um organismo que seja responsável por redigir e aplicar essas regras, além de organizar eventos, credenciar organizações e atletas de forma profissional ou amadora, formular tabelas, calendários e cuidar de todo aparato institucional da modalidade.

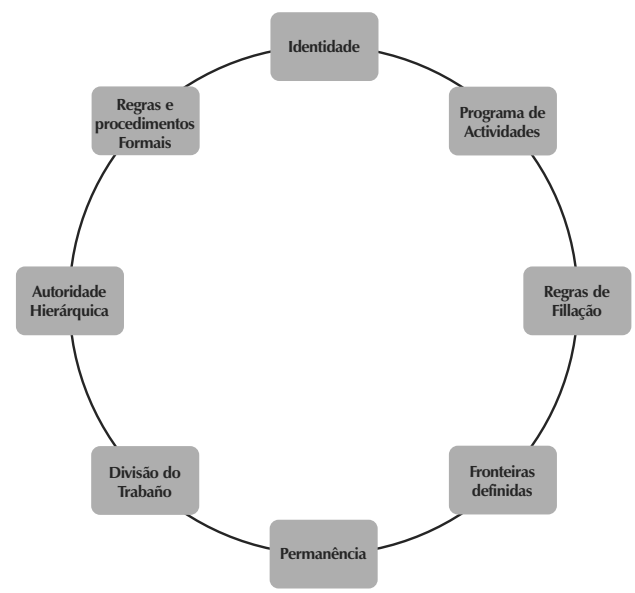

Figura 1. Atributos de uma organização esportiva

Fonte: Chelladurai (2005), apud Ribeiro (2012, p. 26).

A partir do gráfico, entende-se que a identidade é estabelecida com o público para, então, a organização ter como meta o desenvolvimento do esporte através de uma forma institucionalizada. Para isso, é importante estabelecer regras internas, partindo do ponto de esclarecer as formas ingresso, permanência e participação na entidade. As regras para filiação de membros são de fundamental importância, haja vista que os filiados são a principal fonte de poder em uma organização desportiva. Em razão disso, os procedimentos formais são necessários, fazen- do com que a maioria das instituições de governança do esporte possuam estatutos próprios.

Grevemberg (1999, apud Ribeiro, 2012, pp. 26 e 27) aponta itens importantes que devem ser aplicados a uma organização desportiva. Para o autor, se uma organização aplicar esses elementos em sua atuação, ela exercerá a chamada boa governança, dentre as quais são a formulação e aplicação de regras, normas para definir com clareza a modalidade esportiva e suas competições, além de regulamentos para definir a estrutura da entidade e o controle do desporto. Ainda, o autor fala da relação de resultados e publicação para que atletas e público tomem conhecimento da performance e obtenham metas para as competições, da formulação de rankings, onde há o ordenamento dos atletas a partir de seus melhores desempenhos, o que auxilia em diversos casos o apoio financeiro e, por fim, nos recordes, os quais demonstram a evolução de cada categoria em suas modalidades.

Ribeiro (2012, p. 28) apresenta um quadro temático adaptado de Ferkins, o qual aponta as estratégias para o desenvolvimento da governança desportiva. Se dá através de uma dinâmica cada vez mais profissional, impondo um desenvolvimento crescente em todas as áreas no âmbito do esporte, gerando os temas identificados a baixo: 


\section{Dinámica do Ambiente}

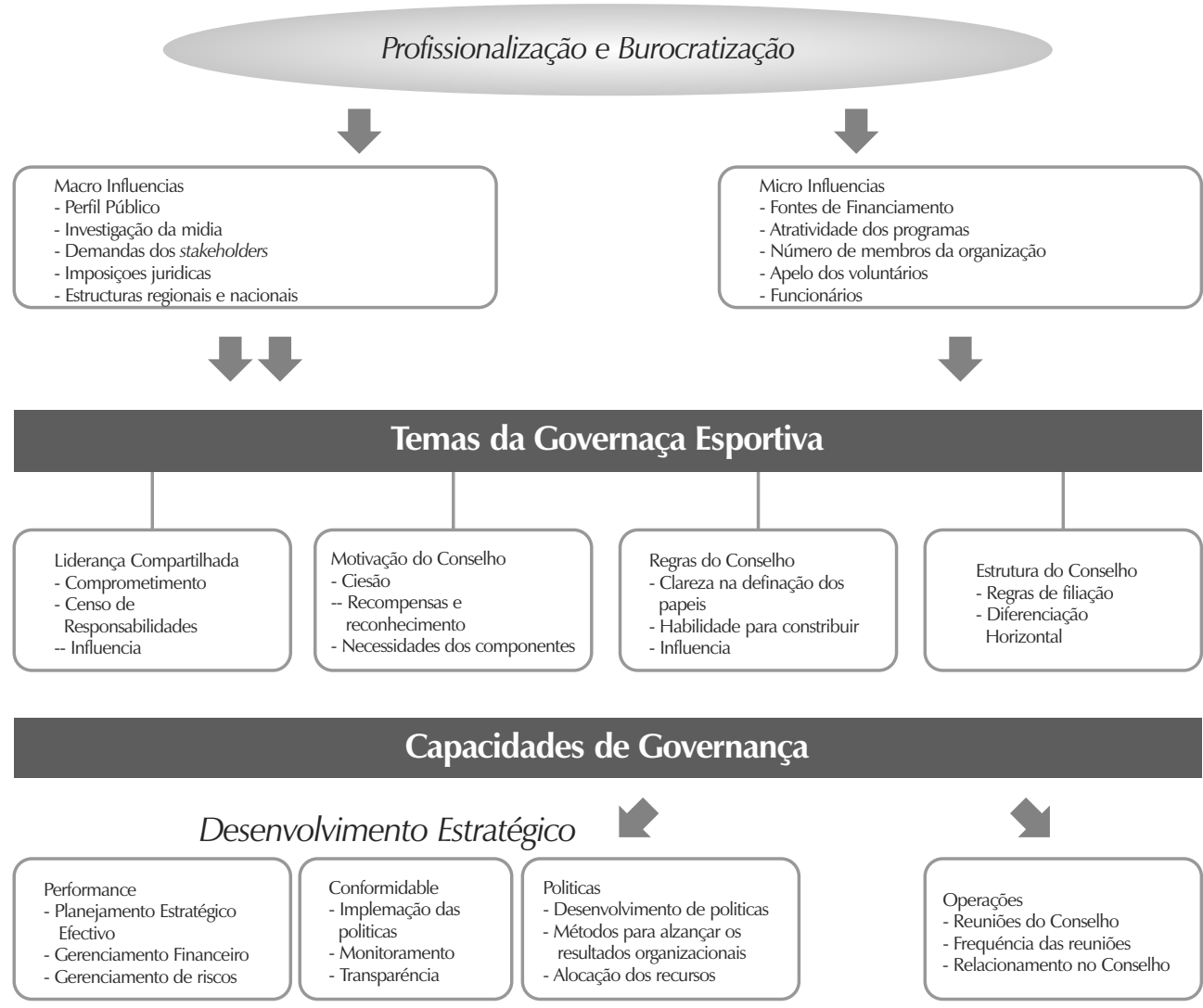

Figura 2. Desenvolvimento governança desportiva

Fonte: Ribeiro (2012, p. 28)

Inglis (1994) elencou alguns elementos necessários para um órgão de organização esportiva: crescimento individual, responsabilidade, contribuição, relacionamento e reconhecimento. Essa profissionalização acaba sendo necessária para o desenvolvimento do esporte e, consequentemente, da governança desportiva, a qual em geral pertence ao chamado Terceiro Setor.
O termo refere-se a um setor fora do mundo dos negócios e do governo, constituído, em tese, por associações não governamentais e sem fins lucrativos, como é o caso das ONG.

Porém, essa conceituação também tem um caráter ideológico neoliberal, pois alguns defendem que o papel do Estado para com as políticas sociais é 
alterado, devendo racionalizar recursos e esvaziar o poder das instituições, consideradas improdutivas pela lógica de mercado. Nesse sentido, há quem defenda que a responsabilidade pela execução das políticas sociais deve ser repassada para a sociedade através de privatização (mercado), e para a Terceira $\mathrm{Via}^{1}$, principalmente através do Terceiro Setor, o qual em tese é sem fins lucrativos (Peroni, 2006), o que vêm a ter consequências nos órgãos de governança desportiva.

De acordo Banco Nacional de Desenvolvimento Econômico e Social, o terceiro setor é definido como o conjunto das atividades privadas com fins públicos e sem fins lucrativos. Além disso, é no espaço de atuação do Terceiro Setor e na organização de empresas associadas voltadas para a disseminação de práticas socialmente responsáveis que observam-se a atual visibilidade da participação das empresas no campo social (Banco Nacional de Desenvolvimento Econômico e Social [BNDES], 2000).

Drucker (1990) versa que se diferenciam organizações com e sem fins lucrativos a partir, principalmente, da missão da organização, dos produtos da mesma, através das estratégias empregadas para vender os seus serviços e obter recursos. De acordo com Ribeiro (2012):
O terceiro setor apresenta novos desafios no âmbito de sua governança, principalmente quando utilizado para executar políticas públicas. O setor público desenvolveu todo um aparelho legal para garantir o bom uso do dinheiro, entre eles: a meritocracia na contratação de funcionários, a formalidade nas aquisições e a transparência na formulação e execução das políticas. Entretanto as organizações do terceiro setor não possuem a estrutura nem a cultura administrativa de cuidar da coisa pública, e sua relação com esse Stakeholder é contratual, podendo servir de burla para as limitações impostas à atuação do serviço público. (p. 24)

Hoye (2010, apud Ribeiro, 2012) aponta as dificuldades que existem para uma eficaz regulação das organizações do chamado terceiro setor. Podemos incluir os órgãos de governança desportiva, dentre as quais aponta a falta de transparência no registro das decisões, a ausência de mecanismos de garantia sobre o cumprimento das obrigações dessas entidades, a incapacidade de coação e de punição aos gestores que descumpram a regulação, a inexistência de suporte gerencial ao terceiro setor e, ainda, ausência de definição clara sobre o que constitui uma organização filantrópica ou do terceiro setor.

A Terceira Via se apresenta como uma alternativa ao neoliberalismo e à social democracia. Giddens (2001, p. 36) aponta que essa chamada Terceira Via seria a atual social democracia, no sentido de que é uma tentativa de transcender tanto a social democracia do velho estilo, quanto o neoliberalismo. 


\section{Futebol e a globalização do esporte}

A FIFA e o COI são as maiores entidades esportivas internacionais, existindo uma relação tensa entre as duas instituições. Porém, ambas conseguiram chegar a esse patamar através de ações visando o controle do esporte perante suas federações filiadas. Observa-se que isso ocorre pois há uma legitimação de suas ações, ou seja, de maneira geral, há uma estrutura coletiva que legitima às decisões de ambas as instituições (Giglio, 2013, p. 111).

Segundo Hilário Franco Júnior (2007), o futebol é um "fenômeno cultural total". Não se observa apenas questões históricas, mas também conceitos antropológicos, análises linguísticas, psicológicas, teológicas, heráldica, entre outros. A inserção do futebol no dia-adia das pessoas é algo que realmente impressiona, está enraizado na cultura de certos países, como o Brasil, ao ponto do país parar para ver o jogo da seleção em época de Copa do Mundo. Sendo o futebol considerado por muitos como o esporte mais praticado do mundo, começa a se entender o alcance do poder da FIFA. É uma das razões que, dentro de um contexto de globalização e do esporte como um negócio, se torna atrativo tornar-se sede de um grande evento FIFA. A partir disso, é possível observar a geopolítica do futebol, como bem observa Favero (2006):

Assim, podemos conceituar a geopolítica como uma fundamentação geográfica de linhas de ação política. Ela estuda os artifícios de controle do espaço e procura entender os diversos interesses que se chocam e se mostram de maneira fragmentada. Como disciplina, a geopolítica trabalha fundamentalmente a relação entre espaço e poder. Ela não é somente utilizada pelo Estado. Pode ser empreendida por entidades, como a Fifa, por exemplo. E assim chega-se à geopolítica do futebol, que trabalha a relação entre o poder do futebol e o espaço do futebol. E essa relação pode ir além: a geopolítica do futebol interfere no poder e a geopolítica do poder interfere no futebol. (p. 13)

Com todo poder que a organização exerce sobre o futebol, desde a geopolítica entre seus filiados, até o controle da jurisdição desportiva de seus litígios, se pode afirmar o monopólio que a FIFA exerce sobre o futebol, com reflexos diretos a nível nacional e internacional. Aponta Arlei Damo (2005):

Na medida em que [a Fifa] detém o monopólio sobre o espetáculo, deixa aos futebolistas opções restritas de mercado para além dos clubes que participam do circuito por ela agenciado. As possibilidades de atuação ou, preferindo-se, de remunerar o capital futebolístico, são limitadas, ainda que exista uma intensa circulação desses profissionais [...] a circulação intensa (sendo as equipes brasileiras renovadas praticamente ano a ano) e extensa, em escala planetária, é característica 
do atual estágio de desenvolvimento do futebol de espetáculo, sendo o mercado incompreensível se não for pensado a partir do monopólio exercido pela Fifa e sua cadeia de agências continentais, nacionais e regionais. (p. 177)

Assim sendo, a expansão do número de países filiados está diretamente ligada à expansão do poder político. Portanto, a entidade segue o caminho do dinheiro, do poder político e do espaço a ser conquistado (Favero, 2006, p.19). Ao longo do tempo, além do aumento do número de federações filiadas, houve também a abrangência do futebol feminino, do futsal e do futebol de areia que reforça ainda mais esse entendimento. No entanto, isso tudo só é possível graças ao "produto" que a FIFA domina, ou seja, o futebol.

Com a saída do ex-presidente João Havelange, e assumindo o mandato no ano de 1998, o suíço Joseph Blatter tem trabalhado cada vez mais para fortificar a hegemonia da FIFA no esporte, usando do soft power para direcionar o futebol para questões sociais, sempre com o slogan da federação. Seus discursos, muitas vezes políticos, por vezes interferem em questões delicadas de diferenças entre Estados, sempre pregando a paz e a união dos povos através do futebol, buscando propiciar e propagar os grandes eventos FIFA em todos os continentes. Contudo, esse tema será melhor analisado ao longo do trabalho, juntamente com toda estrutura, organização e projetos da entidade.

\section{FIFA e governança global}

Com 210 federações afiliadas, o órgão máximo do futebol mundial é chamado de "ONU do futebol" (FIFA, 2013). Somente entre 1975 e 2002, mais de 60 federações foram admitidas como membros. A FIFA oferece ajuda financeira e apoio logístico às federações por meio de diversos programas, garantindo-lhes assim vários direitos e privilégios consideráveis. Por outro lado, também há várias obrigações. Como representantes da FIFA nos seus países, elas precisam respeitar os estatutos, os objetivos e os ideais da organização que rege o futebol mundial. Além disso, devem promover e administrar o esporte de acordo com esses princípios.

A partir do quadro feito por Boniface (2010), pode-se observar o crescimento de ambas as entidades desde seu surgimento, e também que a FIFA praticamente sempre teve mais membros associados ao longo do tempo.

Tabela 1. Comparativo entre Fédération Internationale de Football Association e Organização das Nações Unidas

\begin{tabular}{|c|c|c|}
\hline Ano & $\begin{array}{c}\text { Número de } \\
\text { federações } \\
\text { afiliadas à } \\
\text { FIFA }\end{array}$ & $\begin{array}{c}\text { Número de países } \\
\text { membros da Liga das } \\
\text { Nações ou da ONU }\end{array}$ \\
\hline 1904 & 7 & 0 \\
\hline 1914 & 24 & 0 \\
\hline 1920 & 20 & 42 \\
\hline 1923 & 31 & 43 \\
\hline 1930 & 41 & 41 \\
\hline 1938 & 51 & 38 \\
\hline 1950 & 73 & 60 \\
\hline
\end{tabular}




\begin{tabular}{|c|c|c|}
\hline Ano & $\begin{array}{c}\text { Número de } \\
\text { federações } \\
\text { afiliadas à } \\
\text { FIFA }\end{array}$ & $\begin{array}{c}\text { Número de países } \\
\text { membros da Liga das } \\
\text { Nações ou da ONU }\end{array}$ \\
\hline 1954 & 85 & 76 \\
\hline 1959 & 95 & 99 \\
\hline 1984 & 150 & 159 \\
\hline 1991 & 165 & 166 \\
\hline 1994 & 190 & 185 \\
\hline 2010 & 208 & 192 \\
\hline 2015 & 210 & 193 \\
\hline
\end{tabular}

Fonte: Boniface (2010) (atualizada)

O aumento do número de países filiados à FIFA e também no número de confederações nacionais de futebol feminino, futebol de areia e futsal, estão diretamente ligadas ao desenvolvimento do futebol em suas diversas modalidades, bem como seu objetivo de desenvolver o esporte. Aliado a isso, está o aumento de poder da instituição, que possui total controle sobre o produto futebol.

Dentro das atividades que a federação exerce dentro do futebol, entre as atividades mais importantes é a organização de competições, sendo uma delas um megaevento esportivo, a Copa do Mundo de futebol masculino. Através de seu viés político e econômico, e as bilionárias receitas que ela vem auferindo com o evento, gera para a FIFA transmissão televisiva, venda de ingressos, comercialização de patrocínios, exploração das fan-fests, licenciamento de produtos. Importante também observar a relação que os países sede tem com a entidade, principalmente no atendimento às exigências da FIFA, conferindo a ela mais poder e legitimidade no "jogo dos negócios" (Darn, 2011, pp. 75 e 76).

O quadro a seguir mostra a evolução da Copa do Mundo de futebol masculino ao longo do tempo, mostrando o aumento do público no evento e, principalmente, após a década de 1990, no período onde o termo 'governança global' foi disseminado em meio ao processo de globalização. O aumento de arrecadação da FIFA somente com a venda de direito televisivos é perceptível, atrelado ao aumento de público (tabela 2).

Tabela 2. As edições da Copa do Mundo Fédération Internationale de Football Association

\begin{tabular}{|c|c|c|c|c|c|}
\hline \multirow[b]{2}{*}{ País sede } & \multirow[b]{2}{*}{ Ano } & \multicolumn{2}{|c|}{ Jogos } & \multirow[b]{2}{*}{ Público } & \multirow{2}{*}{$\begin{array}{c}\text { Arrecadação da FIFA somente } \\
\text { com a venda de direitos de } \\
\text { televisão }{ }^{2}\end{array}$} \\
\hline & & $\begin{array}{c}\text { Duração } \\
N^{\circ} .^{\circ} \text { de dias }\end{array}$ & $\begin{array}{l}\mathrm{N} \cdot{ }^{\circ} \text { de } \\
\text { países }\end{array}$ & & \\
\hline África do Sul & 2010 & 30 & 32 & 3.178 .856 & US\$ 3,2 bilhões \\
\hline Alemanha & 2006 & 30 & 32 & 3.353 .655 & US\$ 2,1 bilhões \\
\hline Coréia/Japão & 2002 & 31 & 32 & 2.709 .100 & US\$ 1,2 bilhão \\
\hline França & 1998 & 32 & 32 & 2.923 .000 & US\$ 340 milhões milhões \\
\hline
\end{tabular}

Segundo especialistas, equivale a mais de $50 \%$ da receita do evento. Envolve transmissões ao longo do quadriênio dos jogos, com diversas competições, não só nos dias do evento da Copa (Darn, 2011, p. 76). 


\begin{tabular}{|l|c|c|c|c|l|}
\hline \multirow{2}{*}{ País sede } & Ano & $\begin{array}{c}\text { Juração } \\
\text { N. }{ }^{\circ} \text { de dias }\end{array}$ & $\begin{array}{c}\text { N. }{ }^{\circ} \text { de } \\
\text { países }\end{array}$ & Público & $\begin{array}{c}\text { Arrecadação da FIFA somente } \\
\text { com a venda de direitos de } \\
\text { televisão }{ }^{2}\end{array}$ \\
\cline { 3 - 4 } & 1994 & 31 & 24 & 3.557 .500 & US\$ 103 milhões milhões \\
\hline EUA & 1990 & 30 & 24 & 2.517 .300 & US\$ 90 milhões \\
\hline Mélia & 1986 & 30 & 24 & 2.403 .000 & n.d. \\
\hline Espanha & 1982 & 25 & 24 & 1.855 .200 & n.d. \\
\hline Argentina & 1978 & 25 & 16 & 1.610 .200 & n.d. \\
\hline Alemanha & 1974 & 25 & 16 & 1.774 .000 & n.d. \\
\hline México & 1970 & 22 & 16 & 1.674 .000 & n.d. \\
\hline Inglaterra & 1966 & 20 & 16 & 1.614 .700 & n.d. \\
\hline Chile & 1962 & 19 & 16 & 776.000 & n.d. \\
\hline Suécia & 1958 & 22 & 16 & 868.000 & n.d. \\
\hline Suíça & 1954 & 19 & 16 & 943.000 & n.d. \\
\hline Brasil & 1950 & 23 & 13 & 1.337 .000 & n.d. \\
\hline França & 1938 & 16 & 15 & 483.000 & n.d. \\
\hline Itália & 1934 & 15 & 16 & 395.000 & n.d. \\
\hline Uruguai & 1930 & 18 & 13 & 435.500 & n.d. \\
\hline
\end{tabular}

Fonte: Darn (2011, p. 76).

Ribeiro (2012, p. 12) traz dados do Economy Watch sobre a Copa do Mundo na Alemanha em 2006, que alcançou 27 bilhões de espectadores, tendo rendido à FIFA 2,42 bilhões de dólares em receitas de royalties e direitos de imagem bem como 892,43 milhões de dólares em patrocínios. Ainda, o autor diz que:

Nos casos citados podem ser identificadas duas características importantes: a primeira é a necessidade de participação ativa do Estado no planejamento, infraestrutura e operação desses eventos, e a segunda é o fato de ambas competições pertencerem a organizações do terceiro setor: o Comitê Olímpico Internacional (COI) e a Federação
Internacional de Associações de Futebol (FIFA), ambas com sistemas de governança nos quais os Estados não têm ingerência. (p. 12)

A FIFA tem uma política de valorização e controle do futebol e, ao atuar dessa maneira, consegue aumentar os seus lucros. Entre 2007 e 2010, a receita da entidade passou de US\$2,634 bilhões para US\$ 4,189 bilhões. Os custos também cresceram, mas permaneceram firmemente sob controle, permitindo que a FIFA obtivesse um ótimo resultado de US\$ 631 milhões (Giglio, 2013, p.90).

Além do mundial de seleções, a FIFA tem uma política de valorizar não só simbologias nacionais, mas também 
paixões locais de torcedores por clubes, tendo em vista que são positivas na produção do negócio do futebol. Hobsbawm (2007, p. 93 apud Giglio, 2013, p. 92) afirma que desde que o futebol adquiriu um público de massa, o esporte tem sido o catalisador de duas formas de identificação: a local (com o clube) e a nacional (com a seleção nacional). Além da intenção em aumentar os lucros com a Copa do Mundo de futebol masculino, a FIFA quer fazer com que os torcedores se identifiquem cada vez mais com os seus clubes por meio do pertencimento clubístico (Damo, 2005), além da identificação nacional com a sua seleção, em razão que terá mais patrocinadores investindo para a divulgação de suas marcas para bilhões de pessoas que se interessam por futebol.

Com todo o controle que a federação exerce perante o mundo do futebol, arbitrando as regras do esporte, organizando eventos esportivos, controlando o mercado de transação de atletas, a FIFA possui uma justiça autônoma e independente para resolver litígios. Em seu estatuto ${ }^{3}$, traz como obrigação que as confederações filiadas devem concordar em reconhecer CAS como uma autoridade judicial independente e para assegurar que os seus membros, jogadores e dirigentes filiados cumpram suas decisões. A mesma obrigação se aplica aos intermediários e agentes licenciados de atletas.
O recurso aos tribunais comuns de direito é proibido, a menos que especificamente previstos nos regulamentos da FIFA. Ainda, as associações devem inserir uma cláusula nos seus estatutos ou regulamentos, que estipula que é proibido levar disputas na associação sejam elas sobre competições, clubes, jogadores, funcionários- para tribunais comuns de direito, a menos que os regulamentos da FIFA estipulem isso. As suas associações filiadas devem também assegurar que essa norma seja cumprida, se necessário mediante a imposição de uma obrigação vinculativa para os seus membros, ou seja, sob pena de desfiliação.

\section{Atores da governança global: articulações e disputas}

A FIFA, objeto de estudo dessa dissertação, tem muitas de suas ações legitimadas pelos Estados, onde os mesmos possuem federações que são filiadas à entidade máxima do futebol. Além disso, há uma relação muito grande dos Estados com a FIFA no que tange à sede de competições para o futebol. É interessante para o Estado, importante ator dentro da governança global, que associe seu nome à organização de um evento desportivo. Torna-se atrativo sediar um grande evento FIFA, além da visibilidade que o país terá (sob os pontos de vista social, político e econômico). Há também um sentimento ideológico-nacionalista da população,

68 - Obligation (FIFA, 2015b). 
a movimentação da economia, além do fato de que o país-sede se torna polo turístico mundial durante o evento.

Deve-se questionar muitos aspectos, como o custo bilionário que o Estado deve investir em infraestrutura para sediar o evento, a construção de grandes 'palcos' com padrões estabelecidos pela FIFA, fora a discussão que se deve ter sobre o uso dessas grandes estruturas pós-evento e de medidas que a FIFA exige, tendo em vista interesses próprios, que muitas vezes não vão de encontro com o ordenamento jurídico do país sede. Em relação aos estádios, Gaffney e Mascarenhas (2006) falam que no fim do século passado, a FIFA impôs normas severas para jogos internacionais, como um número mínimo de lugares no estádio e nos estacionamentos, meios de comunicação sofisticados, infraestrutura com "Padrão FIFA", dentre outras várias exigências. Essa ideia do "Padrão FIFA" para os estádios vem sendo aderida pelos clubes não apenas em jogos internacionais, já que essas grandes estruturas se tornam fonte de renda e transformam os clubes e, consequentemente o esporte, em um mercado forte dentro da economia mundial.
Contudo, a FIFA não se relaciona apenas com Estados, mas com outros atores importantes que constituem a chamada governança global. A relação da FIFA com organizações internacionais e não governamentais constituem um papel interessante nessas articulações no âmbito internacional, principalmente pela figura do soft power. A FIFA e a ONU possuem projetos em parceria, onde se observa, primeiramente, que há em todos os jogos da Copa do Mundo a bandeira de ambas nos estádios. Muitos embaixadores da ONU são pessoas relacionadas ao futebol, além de existir programas da ONU, como o Fundo das Nações Unidas para a Infância (Unicef, 2014), que em parceria com a Copa do Mundo FIFA, buscam proteger crianças de violência e abusos, além de dar assistência social aos menores.

Mas a relação da FIFA com a ONU é ainda maior, pois se relacionam também através de outros programas. Um deles é na colaboração para reforçar o papel do desporto na promoção da paz, através da união para a realização dos Objetivos de Desenvolvimento do Milénio ${ }^{4}$. O Assessor Especial do

A virada do século foi interpretada pela ONU como um momento único e simbólico para articular um novo impulso para a Organização. Foram apresentadas recomendações neste sentido pelo então Secretário-Geral Kofi Annan, no seu Relatório do Milénio, "Nós, os Povos, as Nações Unidas do Século XXI". Em Setembro de 2000, Chefes de Estado e de Governo, aprovaram a Declaração do Milénio. A seção III desta Declaração foca o tema "Desenvolvimento e erradicação da pobreza" e foi o principal documento de referência para a formulação dos Objetivos de Desenvolvimento do Milénio. Os Objetivos representam uma parceria entre os países desenvolvidos e os países em desenvolvimento, tendo em vista criar um clima, tanto a nível nacional como mundial, que conduza ao desenvolvimento e à eliminação da pobreza (UNRIC, 2010). 
Secretário-Geral da ONU para o Desporto ao Serviço do Desenvolvimento e da Paz, Wilfried Lemke, foi um dos responsáveis pela parceria, a qual consta no próprio site da ONU, onde o assessor afirma que (Centro Regional de Informação das Nações Unidas [UNRIC], 2008):

Nos últimos anos, muito tem sido conseguido utilizando o futebol, o desporto mais popular do mundo, bem como outros desportos em áreas como a saúde, os direitos das crianças, a educação e a luta contra o racismo, disse
Wilfried Lemke. "Estes esforços ilustram o importante papel que o desporto pode ter na realização dos ODM", acrescentou, elogiando a iniciativa da FIFA Football for Hope, que visa promover os ODM.

A colaboração entre FIFA e ONU ocorre desde a década de 1990, na qual utilizam o esporte como uma ferramenta para a promoção da paz, educação e desenvolvimento. O quadro abaixo é baseado nas principais atividades feitas em conjunto pelas entidades (FIFA, 2011a):

Tabela 3. Relação entre Fédération Internationale de Football Association e Organização das Nações Unidas

\begin{tabular}{|c|c|}
\hline Data & Ações entre fifa e onu \\
\hline Junho de 1999 & $\begin{array}{l}\text { Kofi Annan, Secretário-Geral das Nações Unidas, e Joseph S. Blatter, presidente da } \\
\text { FIFA, reúnem-se em Nova York para anunciar o início da relação entre as respectivas } \\
\text { organizações, destinada a promover os valores que ambos compartilham. }\end{array}$ \\
\hline Junho de 1999 & $\begin{array}{l}\text { O Alto Comissariado das Nações Unidas para os Refugiados (ACNUR), o Fundo das } \\
\text { Nações Unidas para a Infância (UNICEF), a FIFA e a UEFA juntos para trabalhar por } \\
\text { uma causa comum: melhorar, com a ajuda do Futebol, as condições de vida das } \\
\text { crianças de refugiados na área do conflito de Kosovo. }\end{array}$ \\
\hline Janeiro de 2000 & $\begin{array}{l}\text { FIFA e a Confederação Africana de Futebol (CAF) aproveitam a grande oportunidade } \\
\text { do Campeonato Africano das Nações, realizado em Gana e Nigéria, para apoiar a } \\
\text { Organização Mundial da Saúde (OMS) e seus parceiros na campanha "erradicar a } \\
\text { poliomielite na África". }\end{array}$ \\
\hline Novembro de 2001 & $\begin{array}{l}\text { Em } 20 \text { de novembro, na sede da ONU em Nova York, a apresentação da aliança } \\
\text { global entre FIFA e Unicef. A cerimônia contou com a presença, entre outros, de } \\
\text { Joseph S. Blatter, presidente da FIFA; Kofi Annan, Secretário-Geral da ONU; Carol } \\
\text { Bellamy, Diretora Executiva da Unicef; e a lenda do futebol Pelé. }\end{array}$ \\
\hline Abril de 2002 & $\begin{array}{l}\text { FIFA apoia o "Futebol sem tabaco", uma iniciativa da Organização Mundial da } \\
\text { Saúde (OMS) e do Departamento de Saúde e Serviços Humanos (HHS) dos EUA. }\end{array}$ \\
\hline Junho de 2002 & Coreia / Japão 2002 é dedicada à campanha da Unicef "Diga Sim às Crianças". \\
\hline Fevereiro de 2003 & $\begin{array}{l}\text { FIFA e Organização Internacional do Trabalho (OIT) concordaram em colaborar em } \\
\text { uma campanha existente, que é chamado de "Cartão Vermelho para o Trabalho } \\
\text { Infantil" e mostrar o cartão vermelho a exploração do trabalho infantil. O acordo } \\
\text { reúne o mundo do desporto e o mundo do trabalho em uma campanha global sem } \\
\text { precedentes. }\end{array}$ \\
\hline Setembro de 2003 & $\begin{array}{l}\text { A FIFA estabelece a campanha de sensibilização a Unicef na Copa do Mundo } \\
\text { da FIFA de futebol feminino de 2003. "Vamos meninas! Educação para Todas as } \\
\text { Crianças", em uma tentativa de educar o público sobre o direito fundamental à } \\
\text { educação de todas as crianças. }\end{array}$ \\
\hline
\end{tabular}




\begin{tabular}{|c|c|}
\hline Data & Ações entre fifa e onu \\
\hline Dezembro de 2003 & $\begin{array}{l}\text { O primeiro "Jogo Contra a Pobreza" foi realizada após o FIFA World Player Gala do } \\
\text { Ano 2003. A iniciativa, organizada pelo Programa de Desenvolvimento das Nações } \\
\text { Unidas (UNDP) com o apoio da FIFA, reúne Ronaldo, Zinedine Zidane e outras } \\
\text { figuras do futebol no Parque St. Jakob, na Basileia. }\end{array}$ \\
\hline Novembro de 2004 & $\begin{array}{l}\text { A FIFA dedica no Campeonato do Mundo Feminino Sub-19 na Tailândia } 2004 \text { para } \\
\text { a campanha da Unicef "Vá em frente, meninas! Educação para Cada Criança ", em } \\
\text { uma tentativa de educar o público sobre o direito fundamental à educação de todas } \\
\text { as crianças. }\end{array}$ \\
\hline Julho de 2005 & $\begin{array}{l}\text { A FIFA assina a Declaração do Programa de Meio Ambiente das Nações Unidas } \\
\text { (UNEP), ao concordar em adotar e promover a defesa do ambiente e contribuir } \\
\text { para a resolução dos problemas ambientais ao redor do mundo através do desporto, } \\
\text { com o objetivo de criar uma sociedade sustentável. }\end{array}$ \\
\hline Janeiro de 2006 & $\begin{array}{l}\text { FIFA reitera o seu total apoio ao programa da "Erradicação do trabalho infantil na } \\
\text { produção de bolas de futebol" da OIT / IPEC, e várias iniciativas projetado para } \\
\text { destacar a importância dos direitos humanos e educação para as crianças em todo o } \\
\text { mundo. A FIFA tem apoiado financeiramente este programa desde } 1997 \text {. }\end{array}$ \\
\hline Maio de 2006 & $\begin{array}{l}\text { FIFA e Unicef inauguraram oficialmente sua campanha conjunta para a Copa do } \\
\text { Mundo da FIFA Alemanha 2006, o chamado "Juntos pelas Crianças, Juntos pela } \\
\text { Paz". }\end{array}$ \\
\hline Setembro de 2007 & $\begin{array}{l}\text { FIFA e Unicef unem forças para lançar uma campanha "Marcar gol para meninas!", } \\
\text { criado para promover a educação, igualdade de gênero e os direitos das mulheres e } \\
\text { meninas no Mundial Feminino FIFA China } 2007 \text {. }\end{array}$ \\
\hline Janeiro de 2010 & $\begin{array}{l}\text { Realizado em Lisboa VII "Jogo Contra a Pobreza", apoiado pela FIFA. A arrecadação } \\
\text { destina-se ao programa do PNUD no Haiti (FIFA patrocina estes jogos desde 2003). }\end{array}$ \\
\hline Junho de 2010 & $\begin{array}{l}\text { Unicef, em cooperação com os a parceria do governo sul-africano e de ONG, cria } \\
\text { espaços criança, como parte do programa nacional de proteção infantil, em quatro } \\
\text { das Fan Fests da FIFA, em um total de três sedes da Copa do Mundo } 2010 .\end{array}$ \\
\hline
\end{tabular}

Fonte: elaboração própria, com base em dados de FIFA (2011a).

Em 2011, houve uma articulação da FIFA não só com a ONU, mas também com o COI. A relação entre as Nações Unidas e o mundo do desporto aumentou como com o programa do Alto Comissariado das Nações Unidas para os Refugiados (ACNUR) na Namíbia e com a campanha "Juntos podemos parar o HIV e a AIDS" (FIFA, 2011).

Contudo, a FIFA tem parceria também com organizações não governamentais e com instituições privadas. A FIFA colabora com a ONG Street Football World desde 2005 -através de seu comitê de Responsabilidade Social-, quando a instituição viu a oportunidade de cooperar em uma mudança social através do futebol. O Street Football World representou um modelo ideal de aplicação para o desenvolvimento do esporte como um elemento social. A FIFA, desde então, trabalhou para estreitar a colaboração com uma série de projetos, principalmente com o projeto Football for Hope (Street Football World, 2015).

O acesso ao financiamento é um aspecto importante da sustentabilidade 
organizacional. Através do Football for Hope, a Street Football World afirma que a FIFA investe aproximadamente 1,5 milhão de dólares por ano para organizações que usam o futebol para o desenvolvimento social (Street Football World, 2015b). Em 2013 ocorreu o fórum do Football for Hope, reunindo mais de 200 líderes e ativistas, representando organizações e projetos de mais de 50 países diferentes. Os representantes do Street Football World e outras organizações juntaram-se com especialistas dos setores empresarial e acadêmico, com workshops e palestras sobre vários temas os quais o futebol pode colaborar no desenvolvimento. Sessões focadas no papel do futebol nas áreas de liderança, educação, igualdade de gênero, prevenção do HIV/AIDS e construção da paz (Street Football World, 2015a).

Todas as relações da FIFA com os atores no cenário global só se tornam possíveis pela sua relação com instituições privadas. Os patrocinadores -também chamados de parceiros- são importantes para se analisar e entender sua ingerência nas ações da federação, a partir do financiamento da mesma. A FIFA (2012) dispõe que:

De acordo com o artigo 69.. , n.. 2, dos Estatutos da FIFA, a receita e as despesas da FIFA "devem ser administradas de maneira a se equilibrarem após o período financeiro". Além disso, "o cumprimento das principais obrigações futuras da FIFA deve ser garantido por meio da criação de reservas". Aproxima- damente 90\% da receita da FIFA é gerada através da venda de direitos de televisão, marketing, hospitalidade e licenciamento para a Copa do Mundo da FIFA ${ }^{\mathrm{TM}}$. A receita proveniente da comercialização desses direitos e a posse de capital suficiente são de importância crucial para FIFA: além de custear seus diversos programas de desenvolvimento e cobrir custos de operação gerais, a instituição também precisa financiar a organização de diversos torneios internacionais, incluindo, em especial, a Copa do Mundo da FIFA $^{\mathrm{Tm}}$. Quase $70 \%$ das despesas retornam para ações de desenvolvimento do futebol, na forma de suporte financeiro, programas de desenvolvimento e custeio de competições. (p. 22)

Dentre as dimensões que se pode analisar a FIFA, não se pode deixar de entender sua relação com empresas transnacionais que a financiam. Os interesses dessas empresas, além de divulgar suas logomarcas -como as de material esportivo-, podem ainda subverter leis do país-sede. Em virtude de um dos patrocinadores do evento, foi permitida a venda de bebidas alcoólicas nos estádios da Copa do Mundo FIFA 2014 de futebol masculino (Portal da Copa, 2012), ocorrida no Brasil, país onde há uma proibição nesse sentido.

Dentre as modalidades de relações que a FIFA tem com instituições privadas, há os parceiros (FIFA, 2015a), composto por seis empresas para as 
quais a FIFA concede um abrangente pacote de publicidade global em todos os seus eventos. Ainda, há os patrocinadores, que tem direitos exclusivos para ativos de marketing, exposição na mídia e uma associação com eventos especiais da FIFA e iniciativas de desenvolvimento. Por fim, há os chamados apoiadores nacionais, onde o patrocínio é projetado especificamente para a ativação no território onde o evento está ocorrendo e, portanto, é direcionado a empresas nacionais sendo composto de, no máximo, seis empresas (FIFA, 2015).

\section{Darn (2011), aponta que:}

Como podemos observar, seus parceiros são corporações internacionais com atuação em vários países. Suas operações de parceria ou patrocínio são movidas por interesses, devido à publicidade que os eventos da FIFA podem oferecer a estas empresas, tratadas como "Afiliados Comerciais", com privilégios de interesses comerciais [...] Apenas como ilustração, citamos aqui a parceria da FIFA com a HyundaiKia. Segundo o Futebol Finance, site especializado em finanças do futebol, a entidade renovou o contrato com a Hyundai-Kia, patrocinador oficial da FIFA, por mais 12 anos, até 2022, no valor total de cerca de 215 milhões de euros, cerca de 18 milhões de euros por temporada. (p. 22)

Há vários outros tipos de atores com os quais a FIFA possui relações e articu- lações, mas existem também disputas entre alguns desses atores no cenário global sob diversos aspectos. Um desses aspectos é na disputa pelo controle do futebol, na histórica disputa entre a FIFA e o outro grande ator na governança global desportiva, o Comitê Olímpico Internacional (COI).

A principal disputa entre COI e FIFA é para a realização do maior megaevento esportivo. Interesses econômicos e ideológicos, podem ser apontados como fatores fundamentais para a criação da Copa do Mundo FIFA de futebol masculino, a qual teve sua primeira edição em 1930, no Uruguai, como resultado de uma disputa pelo controle do futebol entre as duas entidades. Apesar disso, é possível perceber que a relação entre ambas também é próxima. Membros da FIFA integram o quadro do $\mathrm{COI}$, esse é o caso do presidente da FIFA, Joseph Blatter, membro do COI desde 1999 e João Havelange também foi membro durante 1963 e 2011 (Giglio, 2013, p. 115).

Giglio (2013) afirma que:

Ao longo da história tanto a FIFA quanto o COI, constituíram-se como instituições soberanas. A FIFA controla tudo que se relaciona ao futebol no mundo enquanto ao $\mathrm{COI}$ coube congregar as mais diversas Federações Internacionais das modalidades olímpicas. Embora a FIFA seja uma Federação Internacional, conseguiu um espaço equivalente ao controle exercido pelo COI. O que os une é o fato de possuírem 
o controle dos dois maiores eventos esportivos do planeta: a Copa do Mundo de futebol e os Jogos Olímpicos. A relação entre o COI e a FIFA foi permeada por uma série de disputas em torno do tema do amadorismo e profissionalismo. Nesse jogo político das duas entidades, o que ficava visível era o modo como cada uma delas estava estruturada e como as relações de poder se manifestavam. (p. 104)

Nesse embate histórico, na disputa pelo controle do maior evento internacional de futebol, há algumas questões pontuais que se observam. A primeira e mais clara é que nos jogos olímpicos não se pode usar o símbolo das confederações nacionais no uniforme dos atletas. Ao decorrer do tempo, o embate entre FIFA e COI se deu principalmente na discussão sobre profissionalização ou amadorismo do esporte. A FIFA primou pelo profissionalismo, possui o controle político e financeiro do futebol, criando torneios sub-17 e sub-20, fomentando a Copa do Mundo. Nos jogos olímpicos, há a idade limite de 23 anos para o jogador disputar o torneio olímpico de futebol na modalidade masculina. A tensão entre as entidades já não é tão grande, visto que a FIFA auxilia na organização do futebol nos jogos olímpicos (Agência USP de Notícias, 2014).

Dentro dessa relação, a forma de pensar de ambos os órgãos de governança desportiva é parecida, estando ambas as instituições constituídas dentro dos mesmos princípios. Nesse sentido, sob o ponto de vista financeiro, tanto os Jogos Olímpicos quanto a Copa do Mundo estão estruturados dentro de um mesmo discurso e de uma mesma lógica: da possibilidade de gerar negócios diretos e indiretos (Rubio, apud Giglio, 2013, p. 115-116).

\section{Considerações finais}

A análise feita compreende a governança global no contexto neoliberal, amparada pelos imperativos do capital em escala mundial. Os requisitos da liberdade global na disputa e na relação entre uma multiplicidade de atores com naturezas distintas em termos representativos, são compostos pelo movimento do capital que influencia a forma de governança global sem necessariamente um governo autorizado pelas populações nacionais. O conceito, usado por vezes de forma literal, sofreu o mesmo destino de outros conceitos normativos como "responsabilidade social" ou "desenvolvimento sustentável", tendo sido cooptado por forças hegemônicas do sistema internacional.

Observou-se a FIFA como uma organização não-governamental que se auto apresenta como uma instituição sem fins lucrativos, apesar de seu comportamento oscilar por vezes como mercado, expressando características híbridas e contraditórias na dinâmica da governança global - ora como empresa multinacional, ora como organização do Terceiro Setor, ora como instituição internacional. Ainda, que os organismos de governança desportiva 
se utilizam desse cenário global "sem governo" com pluralidade de atores para atuar e governar em suas específicas áreas, possuindo uma estrutura corporativa baseada na obtenção do lucro para futuros investimentos no esporte. Em termos de número de países filiados, ela ultrapassa o da própria ONU.

Principalmente após a década de 1990, a FIFA vem aumentando o número de competições que organiza, tanto de futebol masculino como feminino, além de ampliar competições de base, clubes, futebol de areia e futsal. Isso faz com que aumente o número de associações filiadas e, consequentemente, legitime ainda mais suas políticas e programas. Ainda, todo e qualquer litígio que ocorre dentro do âmbito do futebol deve ser resolvido dentro da própria justiça desportiva, sob pena inclusive de desfiliação daqueles que buscarem outros órgãos para a resolução dos conflitos, dando a entidade um poder de autonomia e auto regulação, impermeáveis a um maior accountability externo

Esses elementos evidenciam a movimentação da FIFA como um ator dentro do cenário da governança global, inclusive pela sua relação com os demais atores no contexto internacional. Há relações entre FIFA e Estados, tanto no âmbito do futebol -através de suas confederações- como também na sede dos eventos FIFA, principalmente na Copa do Mundo de futebol masculino; há relações da FIFA com o COI na disputa pela organização e controle do futebol - uma relação ba- seada na disputa e na cooperação ao mesmo tempo; há relação da FIFA com empresas transnacionais, através de patrocínio e apoio dos eventos FIFA; e, ainda, há a relação entre a FIFA e outras organizações -internacionais e não-governamentais- através de projetos e programas sociais.

Sob a ótica do soft power, percebe-se que o comportamento contemporâneo da organização procura alinhar-se a discursos democráticos e de accountability, utilizando estratégias de popularização do esporte, ampliando e diversificando as competições e os campeonatos regionais e internacionais, implementando projetos sociais, aumentando parceiros comerciais, entre outras. Para consolidar sua hegemonia internacional pelo controle da organização do futebol em escala global, a FIFA tem utilizado uma série de práticas, discursos e ações estimuladas e incentivadas pela lógica da Governança Global em geral e Governança Desportiva em particular.

\section{Referências}

Agência USP de Notícias (2014). Futebol foi refém de interesses entre FIFA e Comitê Olímpico. São Paulo. Acessado em: < http://www.usp.br/ agen/?p=173960

Banco Nacional de Desenvolvimento Econômico e Social [BNDES] (2000). Empresas, responsabilidade corporativa e investimento social: uma abordagem introdutória. Rela- 
tório Setorial 1. Rio de Janeiro: AS/ GESET.

Boniface, P. (2010). Football et mondialisation. Paris: Armand Colin.

Bourdieu, P. (1983). Questões de sociologia. Rio de Janeiro: Marco Zero.

Bracht, V. (2005). Sociologia Crítica do Esporte. Ijuí: Universidade Regional do Noroeste do Estado do Rio Grande.

Centro Regional de Informação das Nações Unidas [UNRIC] (2008). ONU e FIFA unem-se em prol da realização dos ODM. Bruxelas. Acessado em: <http://www.unric.org/pt/ objectivos-de-desenvolvimento-do-milenio-actualidade/27685-onu-e-fifa-unem-se-em-prol-da-realizacao-dos-odm>

Centro Regional de Informação das Nações Unidas [UNRIC] (2010). Objetivos de Desenvolvimento do Milênio. Bruxelas. Acessado em: $<$ http://www.unric.org/pt/objectivos-de-desenvolvimento-do-milenio-actualidade>

Comitê Olímpico Internacional [COI] (2015). International Sports Federations. Lausana. Acessado em: $<$ http://www.olympic.org/content/ the-ioc/governance/international-federations

Damo, A. S. (2005). Do Dom à Profissão. Uma Etnografia do Futebol de Espetáculo a Partir da Formação de Jogadores no Brasil e na França. (Tese Doutorado). Instituto de Filosofia e Ciências Humanas, Univer- sidade Federal do Rio Grande do Sul, Rio Grande do Sul.

Darn, T. (2011). Reflexões sobre o território do futebol e a copa do mundo FIFA 2014 no Brasil. (Tese Doutorado). Universidade Estadual Paulista, Instituto de Geociências e Ciências Exatas, Rio Claro.

Drucker, P. F. (1990). Managing the non profit organization. Oxford: Butherworth-Heinemann.

Elias, N. e Dunning, E. (1992). A busca da excitação. Lisboa: Difel.

Favero, P. M. (2006). Globalização, mercantilização e geopolítica do futebol. (Tese de doutorado). Universidade de São Paulo, São Paulo.

Fédération Internationale de Football Association [FIFA] (2011). El COI, la FIFA y las Naciones Unidas se dan la mano. Zurique. Acessado em: $<\underline{\text { http://es.fifa.com/sustainability/ }}$ news $/ y=2011 / m=1 /$ news $=$ coi-fifa-las-naciones-unidas-dan-ma$\underline{\text { no-1371240.html }>>}$

Fédération Internationale de Football Association [FIFA] (2011a). A colaboração entre a FIFA e a ONU. Zurique. Acessado em: < http://es.fifa. $\mathrm{com} /$ sustainability/news/y $=2011 /$ $\underline{m}=1 /$ news $=$ colaboracion-entre-fifa-onu-1371188.html>

Fédération Internationale de Football Association [FIFA] (2012). Tudo sobre a FIFA. Zurique. Acessado em: <http://img.fifa.com/ $\mathrm{mm} /$ document/fifafacts/organisation/02/13/11/06/allaboutfifa_por portuguese.pdf $>$ 
Fédération Internationale de Football Association [FIFA] (2013). Associações. Zurique. Acessado em:3 $<$ http://pt.fifa.com/aboutfifa/organisation/associations.html >

Fédération Internationale de Football Association [FIFA] (2015). Additional event sponsorship. Zurique. Acessado em: <http://www.fifa. com/about-fifa/marketing/sponsorship/additional-event-sponsorship. $\underline{\mathrm{html}}>$

Fédération Internationale de Football Association [FIFA] (2015a). FIFA Partners. Zurique. Acessado em: $<$ http://www.fifa.com/about-fifa/ marketing/sponsorship/partners/index.html>

Fédération Internationale de Football Association [FIFA] (2015b). Statutes. Zurique. Acessado em: < http:// www.fifa.com $/ \mathrm{mm} /$ Document/ AFFederation/Generic/02/58/14/ 48/2015FIFAStatutesEN_Neutral. pdf $>$

Franco Junior, H. (2007). A dança dos deuses: futebol, sociedade, cultura. São Paulo: Cia das Letras.

Gaffney, C. e Mascarenhas, G. (2006). The soccer stadium as a disciplinary space. Esporte e Sociedade, n. 1, 1-16.

Giddens, A. (2001). A terceira via: reflexões sobre o impasse político atual e o futuro da social-democracia. Rio de Janeiro: Record.

Giglio, S. (2013). COI x FIFA: a história política do futebol nos Jogos Olímpicos. (Tese Doutorado). Universidade de São Paulo, São Paulo.
Houlihan, B. (1994). Sport and International Politics. Hemel Hempstead: Harvester Wheatsheaf.

Hums, M. A. e MacLean, J. C. (2009). Governance and policy in Sport Organizations. Scottsdale: Holcomb Hathaway.

Inglis, S. (1994). Exploring volunteer board member and executive director needs: Importance and Fulfilment. Journal of Applied Recreation Research, 19(3), 171-189.

Magalhães, L. G. (2013). Com a taça nas mãos: sociedade, Copa do Mundo e ditadura no Brasil e na Argentina. (Tese Doutorado). Universidade Federal Fluminense, Instituto de Ciências Humanas e Filosofia, Departamento de História.

Peroni, V. M. V. (2006). Conexões entre o público e o privado no financiamento e gestão da escola pública. EcCOS, 8, 111-132.

Portal da Copa (2012). Bebidas Alcóolicas. Brasília. Acessado em: < http:// www.copa2014.gov.br/pt-br/tags/ bebidas-alc\%C3\%B3olicas>

Ribeiro, M. A. de S. (2012). Modelos de governança e organizações esportivas: uma análise das federações e confederações esportivas brasileiras. (Tese Mestrado), Escola Brasileira de Administração Pública e de Empresas, Fundação Getúlio Vargas, Rio de Janeiro.

Rosenau, J. N. (2000). Governança, ordem e transformação na política mundial. En J. N. Rpusenau e E. O. 
Czempiel (Orgs.), Governança sem governo: ordem e transformação na política mundial. Brasília: Editora da Universidade de Brasília.

Street Footaball World (2015). FIFA. Berlim. Acessado em: < $\underline{\text { http:// }}$ www.streetfootballworld.org/our-partners/fifa>

Street Football World (2015a). Football for Hope: Forum 2013. Berlim. Acessado em: <http://www.streetfootballworld.org/project/football-hope-forum-2013>
Street Football World (2015b). Football for Hope: Programme Support. Berlim. Acessado em: < http://www. streetfootballworld.org/project/football-hope-programme-support>

Suppo, H. (2012). Reflexões sobre o lugar do esporte nas relações internacionais. Contexto Internacional, 34(2), 397-433.

Unicef (2014). Unicef and the World Cup. Nova lorque. Acessado em: https://www.unicef.org/media/media 33963.html. 